\title{
Oncogenic role of dysregulated leptin signaling in the pathogenesis of ovarian cancer
}

\author{
Iman W. Achkar ${ }^{1}$, Ajaz A. Bhat ${ }^{2}$, Maria Zafar ${ }^{1}$, Madiha Abbas $^{3}$, Omar S. Khan ${ }^{4}$, Shilpa Kuttikrishnan', \\ Kirti S. Prabhu ${ }^{1}$ and Shahab Uddin ${ }^{*^{*}}$ (i)
}

\begin{abstract}
Leptin, a pleiotropic hormone is produced by adipose tissues and plays a critical role in various biological functions. Leptin mediates its function through interaction with specific receptors. The leptin-receptor interaction modulates activation of a number of signaling pathways, such as JAK-STAT, PI3-Kinase-AKT and MAP kinases. Recently, deregulated leptin-mediated signaling has been shown in many cancers including ovarian cancer. A number of studies have shown a link between obesity and carcinogenesis of different cancers via leptin deregulated signaling pathways. In this review, we highlighted the role of deregulated leptin receptor-mediated signaling in the etiology of ovarian cancer.
\end{abstract}

Keywords: Leptin, Ob-R, PI3K/AKT pathway, Ovarian Cancer

\section{Background}

Leptin, a 16-kda protein product of obesity $(\mathrm{Ob})$ gene, has a wide-range of biological functions. Leptin regulates diet intake, formation of bone, reproductive function, and angiogenesis. Leptin is mainly synthesized in white adipose tissues in proportion to triglyceride stores, and serves as an indicator for long-term energy status [1]. However, the ubiquitous presence of leptin receptors in different tissues strongly indicates its multiple roles in human physiology [2-4]. Leptin exists in circulating and bound forms. The circulating level of leptin is increased in obesity and is directly associated with the total body fat mass $[5,6]$. Leptin is capable of mediating a large number of biological functions in a large spectrum of tissues and cell types [7, 8]. In obese patients, the level of leptin is significantly increased and is positively linked to body fat mass $[9,10]$. Many cancers and cancer cell lines showed overexpression of leptin and leptin receptor [11] which has been linked to the pathogenesis of many solid tumors including ovarian

\footnotetext{
* Correspondence: Skhan34@hamad.qa

${ }^{1}$ Translational Research Institute, Academic Health System, Hamad Medical Corporation, POBox 3050, Doha, Qatar

Full list of author information is available at the end of the article
}

cancer [12-17]. However, the evidence linking obesity and ovarian cancer remains greatly controversial [18].

\section{Leptin receptors}

Leptin receptor (Ob-R) belongs to class I cytokine receptor group encoded by $\mathrm{Ob}$ and is expressed in a broad spectrum of tissues [19-21]. There are six alternate spliced Ob-R (Fig. 1) isoforms with different length of cytoplasmic domains, denoted as Ob-Ra, Ob-Rb, Ob-Rc, Ob-Rd, Ob-Re, and Ob-Rf [20, 22]. Only Ob-Rb is capable of transducing signals into the cell through its cytoplasmic region. The cytoplasmic region of $\mathrm{Ob}-\mathrm{R}$ is made up of various motifs necessary for signaling functions of leptin. The role of other Ob-R isoforms remain to be elucidated. As shown in Fig. 2, the extracellular domain of $\mathrm{Ob}-\mathrm{R}$ contains various structural domains including an $\mathrm{N}$-terminal cytokine, receptor homology domain (CRH-1); an immunoglobulin-like (Ig) domain; a second CRH domain (CRH-2), also known as the leptin-binding domain (LBD); and two Fibronectin type III (FNIII) domains [23]. Ob-Rb is found to be defective in $\mathrm{C} 57 \mathrm{Bl} / \mathrm{Ks} \mathrm{db} / \mathrm{db}$ mice $[24,25]$. An identical phenotype is also observed in mice having null mutations of the leptin receptor or leptin itself $[24,25]$. These studies show the crucial role of $\mathrm{Ob}-\mathrm{Rb}$ isoform in leptin-mediated signaling in mammalian cells. Moreover, Obesity-associated diabetes 


\section{Leptin receptor variants}

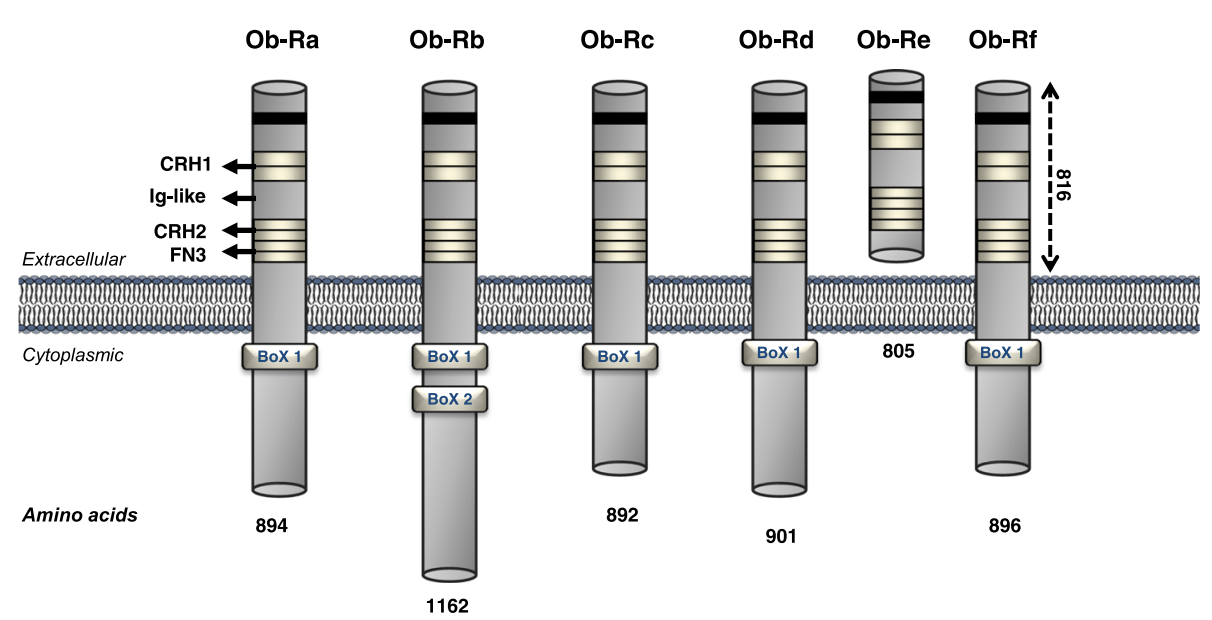

Fig. 1 Variants of Leptin Receptor

has been reported due to genetic deficiency in leptin or leptin receptor Ob-R genes.

\section{Leptin-mediated signaling}

Leptin regulates various signaling pathways in many human cancers (Fig. 3). The main pathways governed by leptin are; JAK2/STAT3 (Janus kinases/ transducer and activator of transcription3), IRS1/2-PI3K/AKT (Insulin receptor substrate/ phosphatidylinositol 3-Kinase/Protein kinase B), SHP2/ERK (Src Homology Phosphatase 2/ Extracellular Signal-Related Kinase), and COX-2 (Cyclooxygenase) [19, 26-28]. The following section summarizes the pathways involved in leptin signaling.

\section{JAK2/STAT3 pathway}

Leptin signaling is initiated by binding of leptin to its receptor which results in the activation of JAKs, a family comprised of four members: JAK1, JAK2, JAK 3 and Tyk2. JAKs are critical signaling pathways that participate in almost all cytokines and growth factor mediated biological functions. JAK2 is the primary kinase which takes part in leptin signaling. Tyrosine phosphorylation of $\mathrm{Ob}-\mathrm{Rb}$ at $\mathrm{Tyr}$ 1138 by JAK2 leads its binding to STAT3, which is the main transcription factor phosphorylated/activated by leptin. However, other STAT proteins such as STAT1, STAT5, and STAT6 have also been shown to be activated by leptin [29-31]. Translocation of STAT3 to the nucleus is mediated by homodimerization of phosphorylated STAT3. The phosphorylated STAT3 binds to the promoter of many genes and stimulates their transcription (Fig. 2). The JAK/ STAT-regulated genes play essential functions in growth and proliferation of many cancer cells $[29,32,33]$. The box 1 motif of the intracellular domain of Ob-R is a critical component for activation by JAK2. The box 1 motif contains a sequence found in all leptin receptor isoforms. Interestingly, $\mathrm{Ob}-\mathrm{Rb}$ is a unique receptor isoform in which intracellular tyrosine residues are conserved and can activate a number of downstream signaling pathways [34, 35]. The Ob-Rb also has a cytokine box 2, which lacks the ability to activate JAK2, however a sequence of 15 amino acid which is present downstream of box 1 can activate JAK2 [36, 37].

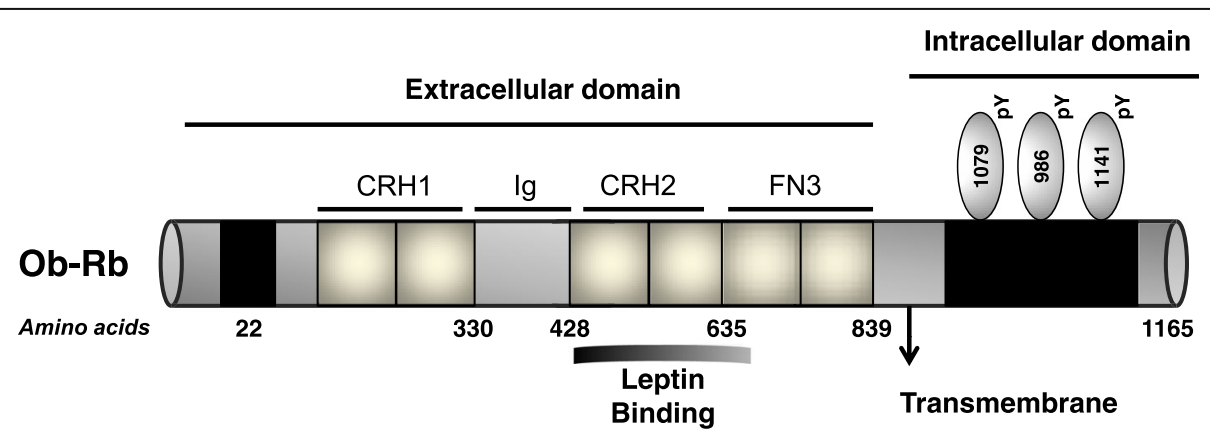

Fig. 2 Schematic representation of functional leptin receptor (a long isoform of the leptin receptor, Ob-Rb) 


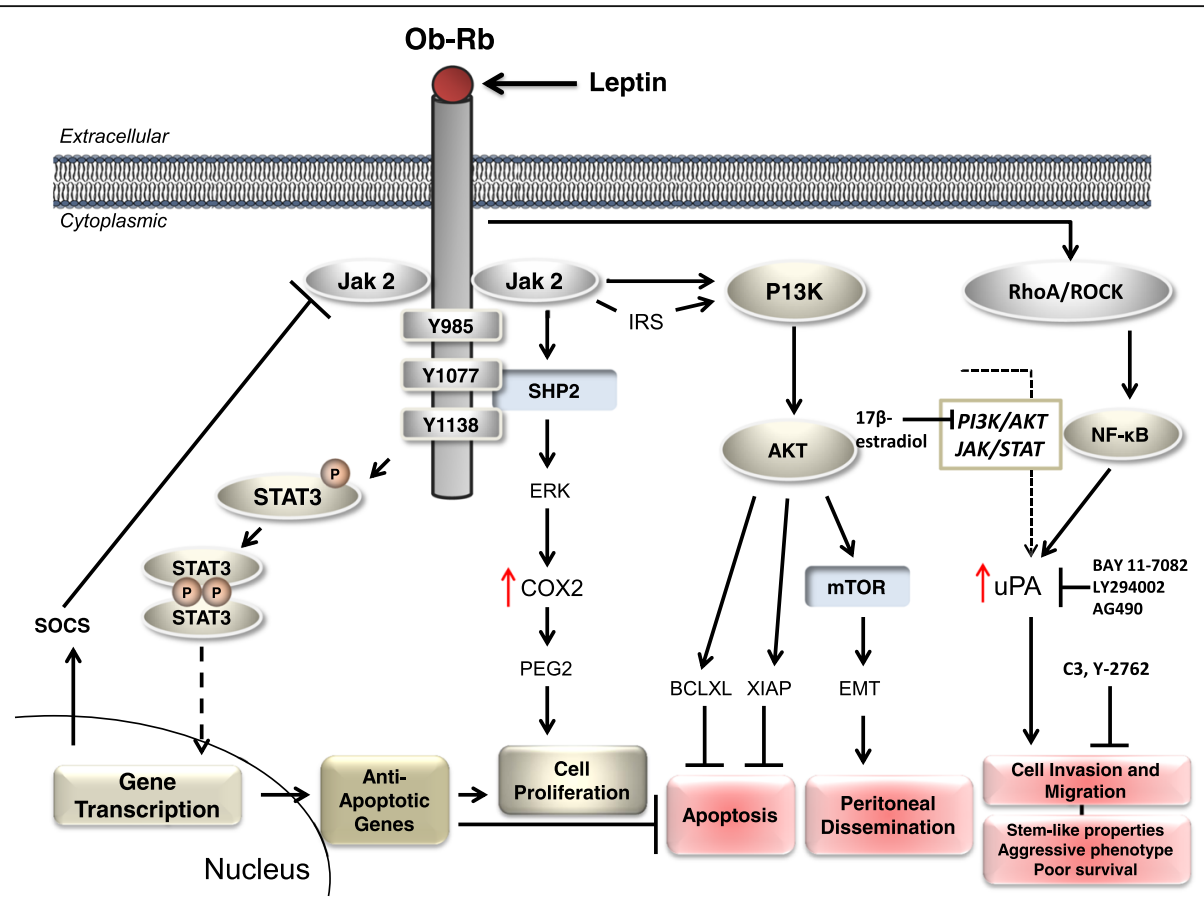

Fig. 3 Schematic representation of leptin-mediated signaling. Leptin binds to Ob-Rb and activates Janus-family tyrosine kinase 2 (JAK2) by autophosphorylation. Activated JAK2 then phosphorylates the other tyrosine residues Tyr985, Tyr1077, and Tyr1138. These phosphorylated amino acid residues act as sites for the binding of intracellular signaling molecules. Tyr1138 on Ob-Rb is crucial for STAT3 activation, which stimulates SOCS3 expression as well as other genes expression are involved in cell proliferation. SOCS3 can negatively regulate leptin signaling via inhibiting JAK2 activity in a feedback mechanism. JAK2 phosphorylation can lead to activation of PI3-Kinase /AKT pathway trough JAK2 as well as via insulin substrate. The activated PI3-kinase/AKT regulates cell proliferation via modulation of antiapoptotic genes such as BcXL and XIAP. 17ß-estradiol, an estrogen steroid, can reverse leptin-induced migration via PI3K-Akt pathway. Ob-Rb can also activate MAP-kinase and COX-2 signaling pathways. Leptin-mediated increase of COX-2 expression is correlated with increased proliferation. Leptin induces EMT via PI3K/Akt/mTOR pathway, associated with malignant transformation and peritoneal dissemination. Leptin binding also upregulates UPA, mediated by RhoA/ROCK pathway, inducing cancer cell migration and invasiveness. PI3K/AKT and JAK/STAT pathways can also upregulate uPA expression. Leptin-induced migration/invasion via the mentioned pathways maintains stem-like properties and mesenchymal phenotype, potentially explaining the poor survival outcome in obese women

\section{PI3-kinase/AKT pathway}

The association between Leptin/Ob-R and PI3K/AKT has been found in many epithelial tumors [32, 33, 38-40]. PI3K/AKT pathway can be activated via both receptor tyrosine kinases and non-receptor tyrosine kinases [41]. Leptin mainly acts through JAK/STAT but PI3K signaling pathway has also been shown to participate in leptin generated signals in many cell types [42]. Leptin via Ob-R and JAK2 kinases activates PI3K and AKT through docking protein insulin substrate (IRS). Activated PI3K converts phosphatidylinositol 3-phosphate (PI) and phosphatidylinositol 4, 5-bisphosphate (PIP2) to phosphatidylinositol 3, 4, 5-trisphosphate (PIP3) in the plasma membrane. Pleckstrin homology $(\mathrm{PH})$ domain-containing proteins can bind to PIP2 and PIP3 which leads to alterations in the conformation of these proteins. AKT is one of the several proteins that contains $\mathrm{PH}$ domain [43] and can be activated by PI3K via PIP molecules resulting in its translocation to the cell membrane. The threonine residue (T308) in AKT central kinase domain binds to the phosphoinositide-dependent protein kinase 1 (PDK1) and a C-terminal tail domain at a serine residue (S473). For full activation of AKT, T308 and S473 amino acid residues are required to be phosphorylated. The PI3K/AKT pathway controls many signaling cascades to regulate multiple cellular functions, such as cell proliferation, apoptosis, and cell motility [43].

In vitro studies using epithelial ovarian cancer (EOC) cells have shown that dysregulated expression of leptin/leptin receptor is linked with oncogenic effects which lead to an increase in cell proliferation and reduction in apoptotic cell death. Leptin treatment of EOC cells rapidly increases cell proliferation via activation of PI3/AKT and its associated pathways. Leptin-induced activation of PI3-K/AKT can be prevented by LY29402, a PI3K inhibitor which leads to dephosphorylation/inactivation of AKT in EOC cell lines. Furthermore, knockdown of Ob-R gene by using Ob-R specific siRNA in EOC cells also reduces X-linked inhibitor of apoptosis protein (XIAP) and B-cell lymphoma-extra large $(\mathrm{Bcl}-\mathrm{xL})$ gene expression. These findings strongly suggest that leptin-mediated PI3K/AKT pathway is involved in EOC cell growth and proliferation via regulation of the gene expression of antiapoptotic gene. 
Furthermore, the estrogen steroid, $17 \beta$-estradiol, has also been found to reverse leptin-induced migration and display an antagonistic effect on Matrix metallopeptidase (MMP)-9 expression and activity in ovarian cancer cells via PI3K-Akt pathway [44] (Fig. 3). These findings were confirmed by pre-treatment with PI3K inhibitor, LY294002, which reversed these effects. The biology of ovarian cancer is very distinct from other types of cancer, considering the immensely high estrogen levels and ovarian tissue exposure to $17 \beta$-estradiol, which promotes cancer cell migration and potential interaction with other hormones. Therefore, the necessity of understanding the correlation between $17 \beta$-estradiol and leptin is crucial. This study, for the first time, provided evidence of a $17 \beta$-estradiol antagonistic effect on leptin-induced cancer cell migration, and identified PI3K as the cell signaling pathway which [45]provides much-needed insight into the link between $17 \beta$-estradiol, cancer cell migration and leptin at a physiological level specifically in ovarian cancer.

Interestingly, it has also been found that leptin induces epithelial-mesenchymal transition (EMT) in ovarian cancer cells via the activation of the PI3K/Akt/ mechanistic target of rapamycin (mTOR) pathway. This was further supported by the study where PI3K/Akt/mTOR pathway inhibition resulted in the impairment of leptin-induced malignant transformation of ovarian cancer cells.. In vivo xenograft model also revealed that the peritoneal dissemination of ovarian cancer cells could be significantly inhibited by blocking leptin signaling. These studies reflect the importance of leptin in ovarian cancer cell progression while presenting new insights into leptin involvement in ovarian cancer metastasis via novel PI3K/Akt/mTOR pathway.

\section{ERK pathway}

ERK is a member of the mitogen-activated protein kinase (MAPK) family, which functions in association with the Ob-Rb. Activation of ERK1/2 is regulated by SHP2 which phosphorylates Ob-Rb at Tyr985 or is directly governed by JAK2 [19]. Inactivation of hypothalamic ERK1/2 prevents leptin-mediated weight loss in animal models. Inactivation of ERK activity also blocks leptin-mediated sympathetic activation of fat tissue, implicating the role of MAPK signaling in diet intake and energy expenditure [34].

A recent study by Chen et al. [45] explored the cell signaling pathways which mediate the effects of leptin and their mechanism of action. The leptin-mediated interaction between the MEK/ERK/1/2 and PI3K/AKT signaling was able to stimulate the growth of ovarian cancer cells. Furthermore, leptin inhibits apoptosis by upregulation of cyclin D1 and myeloid leukemia cell differentiation protein (Mcl-1).

\section{COX2 pathway}

COX is a critical enzyme involved in the production of prostaglandins (PGs) via conversion of arachidonic acid.
COX-1 and COX-2 are two isoforms of the COX gene. Human COX-2 gene has been found to be overexpressed in various tumors and is linked to tumorigenesis, metastasis, and angiogenesis $[46,47]$. COX-2 regulates AKT pathway to sustain the growth and survival of many cancer cells [48]. The COX-2 expression has been found to be regulated by activation of JAK2 mediated AKT and MAP kinase pathways in OE33 esophageal adenocarcinoma cells. [49]. A similar observation was reported where leptin-mediated upregulation of COX-2 transcription resulted in PGE2 secretion by endometrial cancer cells [29] (Fig. 3). Furthermore, a leptin-mediated increase of COX-2 expression correlated with increased proliferation of endometrial cancer cell lines [29] (Fig. 3).

Moreover, in a current study by Ghasemi et al. [50], a new mechanism of action has been suggested in facilitating leptin-induced cancer cell invasion. By investigating the contribution of Urokinase plasminogen activator (uPA), a biomarker of tumor cell invasion and metastasis [51], leptin was identified to upregulate uPA in a time and dose-dependent manner, inducing invasion and metastasis in ovarian cancer cell lines (Fig. 3). Pre-treatment of cells with the inhibitors of PI3K/AKT (LY294002), JAK/STAT (AG490) and NF-kB (nuclear factor kappa-light-chain-enhancer of activated B cells), BAY 11-7082), significantly reduced leptin-induced uPA expression [50]. Furthermore, pre-incubation with Ras homolog gene family member A/ Rho-associated protein kinase (RhoA/ROCK) inhibitors (C3 and Y-27632) inhibited the invasiveness of ovarian cancer cells and leptin-induced upA expression [50] This illustrates not only the involvement of JAK/STAT and PI3K/ AKT signaling pathways but other associated pathways, such as RhoA/ROCK, and their ability to mediate leptin-induced cancer cell migration and invasiveness in ovarian cancer cells.

\section{Leptin and ovarian carcinogenesis}

Ovarian cancer is a prominent cause of gynecological cancer mortality in the West and EOC constitutes 80-90\% of all ovarian cancers [52-56]. Dysregulation of leptin signaling has been linked to the pathogenesis of many epithelial cancers including EOC [32, 49, 57, 58].

Decreased levels of adiponectin, another obesity-related hormone and adipokine, has also been associated with the development and progression of ovarian cancer. Whereas normal levels of adiponectin are otherwise involved in the suppression of cancer cell growth, invasiveness, and inhibit angiogenesis [59]. This association has been further explored in a recent study by Jin et al. which provided evidence that decreased plasma adiponectin (8.25 vs. $11.44 \mu \mathrm{g} /$ $\mathrm{mL}$ ) and leptin levels (7.09 vs. $15.4 \mathrm{ng} / \mathrm{mL}$ ) were found in patient samples compared to control group and were associated with the risk of developing ovarian cancer. Although higher levels of leptin have been reported in few cases of 
ovarian cancer, majority of the findings identified low leptin levels to be responsible for the cancer. [60-63]

Furthermore, an epidemiological study [64] has reported that ovarian cancer is more common in obese women as compared to women with healthy weight. More recently, the clinical outcome of 70 patients with ovarian cancer, validated from the Cancer Genome Atlas (TCGA) database, was assessed [18] while investigating the impact of overweight/ obesity and the effect of leptin on the metastasis of ovarian cancer cells. Patients exhibiting higher levels of leptin and $\mathrm{Ob}-\mathrm{Rb}$ were found to have a worse overall survival rate and higher leptin levels in particular were found in overweight patient serum, and ascite samples; a shared symptom of advanced ovarian cancer patients [65]. Ob-Rb expression levels were also higher in ascites and metastases compared to primary tumors. Moreover, leptin was shown to increase ovarian cancer cell migration and invasion via JAK-STAT3, PI3K/AKT, and RhoA/ROCK and maintained stem-like properties and mesenchymal phenotype, potentially explaining the poor survival outcome in obese women. Leptin eventually promotes a more aggressive phenotype in ovarian cancer cells, which could support the overall worse prognosis among obese cancer patients [66].

Although a link between hormonal dysregulation in ovarian cancer and obesity has been suggested, and that circulating levels of leptin has been reported to be increased in gynecological cancers [67], the mechanism of risk associated with obesity and the link with EOC is still not fully understood.

In endometrial cancer, $\mathrm{Ob}-\mathrm{Rb}$ is associated with body mass index [68]. Ob-Ra and Ob-Rb are expressed in normal tissues, but their expression was found to be five-fold higher in cancer tissues [68]. A recent study shows that microRNAs specifically targeting Forkhead box O3 (FOXO3) can increase the proliferative effect of leptin in EOC cells [69]. A study by Uddin et al. [15] demonstrated $59.2 \%$ of EOC patient samples express high-level of leptin receptors. A significantly poor disease-free survival is observed in patients with high-level of Ob- $\mathrm{R}$ expression compared with the patients of low-level Ob- $\mathrm{R}$ protein expression, suggesting a critical role of leptin signaling in the pathogenesis of EOC [15]. These results support findings of another study where enhanced expression of $\mathrm{Ob}-\mathrm{R}$ was detected in biopsies of patients with ovarian cancer [70]. Furthermore, Ob-R overexpression is linked to aggressive behavior in many cancers including colon cancer, papillary thyroid and diffuse large B-cell lymphoma $[16,71,72]$. The aggressive phenotype of these malignancies can be explained by a strong association of leptin/Ob-R with antiapoptotic signaling including PI3K/ AKT and MAP kinase [32, 34, 38, 40, 58, 73]. Although no direct correlation between AKT and Ob-R was seen in EOC, however, Ob-R expression was significantly associated with activated Glycogen synthase kinase 3 (GSK3) and Phosphatase and tensin homolog (PTEN) protein [15]. In addition, $\mathrm{Ob}-\mathrm{R}$ was found to be significantly associated with $\mathrm{Bcl}-\mathrm{XL}$ and XIAP, the downstream substrates of PI3K/AKT signaling [15]. Furthermore, expression of leptin was significantly associated with activated AKT in EOC patient samples suggesting a link between leptin and PI3K signaling in ovarian cancers [15].

The in vitro study utilizing a panel of cell lines indicated that dysregulated leptin/leptin receptor expression has oncogenic effects in EOC cells. Leptin strongly activates PI3K/AKT pathway via phosphorylation of AKT at ser473 residue. Blocking of leptin-mediated activation of PI3K/AKT signaling by LY294002, a pharmacological inhibitor of PI3K, prevents AKT activity. Furthermore, knockdown of Ob-R inactivated AKT and suppressed the expression of XIAP and Bcl-XL genes in EOC cell lines. These findings suggest that leptin-mediated regulation of antiapoptotic genes plays a role in growth and survival of EOC cells. In an earlier study by Chen et al. [45] it was also reported that treatment of OVCAR-3 cell line with leptin promoted proliferation of these cells in a dose-dependent manner. In addition, leptin treatment led to phosphorylation of STAT3 and ERK1/2 as well as inhibition of caspase activation [74]. Leptin was also found to enhance the expression of cyclin D1 and Mcl-1 genes suggesting a role of these genes in leptin-mediated proliferation and the inhibition of apoptosis in ovarian cancer [45]. Furthermore, leptin-mediated activation of the MAPK and PI3K/AKT signaling pathways was blocked by the treatment of ovarian cancer cells either with LY294002 or PD98059, a specific inhibitor of PI3-kinase and MAPK respectively. These findings also suggest a cross-talk between PI3K/AKT and MEK/ ERK1/2 pathways in sustaining the leptin-mediated proliferation of ovarian cancer cells [45].

Moreover, several leptin receptor antagonists have been synthesized and introduced into pre-clinical studies for therapeutic use in anticancer treatment, however, the information regarding the application of leptin receptor blockers towards ovarian cancer is limited [75] . Two antagonists in particular, superactive human leptin antagonist (SHLA) and quadruple leptin mutein, Lan-2 (L39A/ $\mathrm{D} 40 \mathrm{~A} / \mathrm{F} 41 \mathrm{~A} / \mathrm{I} 42 \mathrm{~A}$ ), were evaluated in a study by Fiedor et al. [75] for their effect on cell proliferation and cell signaling pathways in ovarian epithelial cells. It was demonstrated that although both ObR blockers inhibited cdk/ cyclin D1 cell cycle progression in metastatic carcinoma cell line, in serous carcinoma however, the effect was limited to cdk2 and cdk4 protein expression. SHLA also had an inhibitory effect on all signaling pathways investigated, including STAT3, ERK1/2, and AKT, in serous carcinoma while only on STAT3 in metastatic carcinoma, and Lan-2 had an inhibitory effect on STAT3, ERK1/2 in metastatic carcinoma and AKT protein phosphorylation in serous carcinoma. These findings demonstrate SHLA and Lan-2 
abilities in blocking leptin receptor activity in ovarian cancer, however, when selecting a specific ObR antagonist, the related tumor type should be considered.

\section{Conclusion and future perspective}

Aberrant expression of leptin and Ob-R indicates leptin as mitogenic, transforming and angiogenic factor. Several studies have provided evidence for the possible role of leptin in the pathogenesis and development of numerous cancers including epithelial ovarian cancer. Dyregulated expression of $\mathrm{Ob}-\mathrm{R}$ and altered levels of leptin in patient serum has been confirmed by a number of in vitro, in vivo studies and in clinical samples (Table 1). Despite substantial evidence that leptin and leptin receptor expression is deregulated in ovarian cancers, these results are still limited and inconclusive. Few studies also suggest the presence of a short form of the leptin receptor, however, its function is still not known. Further research is needed

Table 1 Leptin / Leptin Receptor mediated effects in Ovarian Cancer

\begin{tabular}{|c|c|c|c|}
\hline $\begin{array}{l}\text { Leptin/Leptin Receptor } \\
\text { expression or their action }\end{array}$ & Model/System & Mechanism of Action & Reference \\
\hline Leptin mediated Effects & OVCAR-3 & $\begin{array}{l}\text { Leptin inhibits caspase-3 expression and activity by modulating STAT3 } \\
\text { and ERK1/2 signaling pathways in OVCAR-3 cells. }\end{array}$ & {$[74]$} \\
\hline Leptin mediated Effects & OVCAR-3 and SKOV-3 & $\begin{array}{l}\text { Leptin stimulates cell migration via MMP-9 expression and activity in } \\
\text { OVCAR-3 but not SKOV-3 }\end{array}$ & {$[44]$} \\
\hline Leptin mediated Effects & & $\begin{array}{l}\text { 17ß-estradiol displayed antagonistic effect on leptin-induced cell migration } \\
\text { and MMP-9 expression and activity }\end{array}$ & {$[76]$} \\
\hline Leptin mediated Effects & OC cells & $\begin{array}{l}\text { Leptin induces EMT via PI3K/Akt/mTOR pathway activation. Inhibiting PI3KV } \\
\text { Akt/mTOR impaired leptin-induced malignant transformation }\end{array}$ & \\
\hline Leptin mediated Effects & & $\begin{array}{l}\text { Blocking Leptin inhibited peritoneal dissemination and suppressed ovarian } \\
\text { malignant ascites-induced metastatic aggravation }\end{array}$ & \\
\hline Leptin mediated Effects & OVCAR3, SKOV3 and CaoV-3 & $\begin{array}{l}\text { Leptin induced cell invasion via up-regulating uPA. Ob-Rb, RhoA/ROCK, } \\
\text { PI3KVAKT, JAK/STAT pathways and NF-kB activation were involved in } \\
\text { leptin-induced UPA expression }\end{array}$ & {$[50]$} \\
\hline Leptin Receptor Expression & 35 Ovarian Cancer Patients & $\begin{array}{l}\text { Endometrial neoplasms and long leptin isoform receptor expression } \\
\text { were associated with an increased BMI. A role of long isoform in } \\
\text { endometrial carcinogenesis is proposed. }\end{array}$ & {$[68]$} \\
\hline Leptin mediated effects & OCCAR-3 & $\begin{array}{l}\text { Leptin upregulates the expression of cyclin D1 and } \mathrm{Mcl}-1 \text { to stimulate } \\
\text { cell growth by activating the PI3K/AKT and MEK/ERK1/2 pathways in } \\
\text { ovarian cancer. }\end{array}$ & {$[45]$} \\
\hline Leptin expression & BG-1, OVCAR-3, and SKOV-3 & $\begin{array}{l}\text { Both short and long isoforms of leptin receptors are expressed in } \\
\text { IOSE-80PC (a post-crisis line), cells. In addition, treatment with leptin } \\
\text { resulted in the growth stimulation of BG-1 cells, an activation of ERK1/2 } \\
\text { and inhibition of constitutive phosphorylation of p38 MAPK }\end{array}$ & {$[58]$} \\
\hline $\begin{array}{l}\text { Leptin expression \& } \\
\text { Its Effects }\end{array}$ & OC cells & $\begin{array}{l}\text { Leptin was highly expressed, promoting cell migration, invasion and } \\
\text { proliferation, resulting in poor survival }\end{array}$ & {$[76]$} \\
\hline Leptin level & $\begin{array}{l}52 \text { OC patients vs } 50 \text { control } \\
\text { group with benign disease }\end{array}$ & $\begin{array}{l}\text { Decreased leptin levels compared to control group (7.09 vs. } 15.4 \mathrm{ng} / \mathrm{mL}) \text {, } \\
\text { associated with risk of developing OC }\end{array}$ & {$[59]$} \\
\hline Serum Leptin & 167 endometrial cancer cases & $\begin{array}{l}\text { Elevated leptin levels showed a positive association with endometrium } \\
\text { cancer }\end{array}$ & {$[61]$} \\
\hline Leptin mediated action & SKOV3 and A2780 cells & $\begin{array}{l}\text { Cross-talk between leptin and microRNA-182 and microRNA-96 affects } \\
\text { the transformation and proliferation of ovarian cancer cells. }\end{array}$ & {$[69]$} \\
\hline Serum Leptin & $\begin{array}{l}30 \text { patients with endometrial } \\
\text { cancer }\end{array}$ & $\begin{array}{l}\text { Leptin did not show any significant correlation with stage, grade, } \\
\text { histological type and node metastases in endometrial cancer. }\end{array}$ & {$[77]$} \\
\hline $\begin{array}{l}\text { Leptin Receptor expression } \\
\text { and leptin mediated action }\end{array}$ & $\begin{array}{l}156 \text { EOC samples and EOC } \\
\text { cell lines. }\end{array}$ & $\begin{array}{l}\text { Ob-R overexpression (59.2\%) in EOC samples was significantly associated } \\
\text { with poor progression free survival. Leptin promotes cell proliferation via } \\
\text { activation of PI3-kinase/AKT signaling. }\end{array}$ & {$[15]$} \\
\hline \multirow[t]{2}{*}{ Serum and ascite samples } & 70 OC patients & & {$[18]$} \\
\hline & & $\begin{array}{l}\text { Higher leptin and Ob-Rb levels, resulting in poor survival, higher leptin } \\
\text { in overweight patient serum and ascite samples }\end{array}$ & \\
\hline Leptin Receptor Expression & & $\begin{array}{l}\text { Ob-Rb expression levels higher in ascites and metastases compared to } \\
\text { primary tumors. }\end{array}$ & \\
\hline Leptin mediated action & & $\begin{array}{l}\text { Leptin increased cell migration and invasion via JAK-STAT3, PI3K/AKT, and } \\
\text { RhoA/ROCK, maintained stem-like properties and mesenchymal phenotype, } \\
\text { explaining poor survival outcome }\end{array}$ & \\
\hline
\end{tabular}


to examine the detailed molecular mechanisms of leptin involvement in gynecological cancers and targeting leptin/ leptin receptor could offer a potential therapeutic strategy against ovarian cancer development and metastasis.

\section{Abbreviations}

BCl-xL: B-cell lymphoma-extra large; COX: Cyclooxygenase; CRH-1: Receptor homology domain; $\mathrm{CRH}-2$ : Second $\mathrm{CRH}$ domain; EMT: Epithelialmesenchymal transition; EOC: Epithelial Ovarian Cancer; EOC: Epithelial ovarian cancer; ERK: Extracellular Signal-Related Kinase; FNIII: Fibronectin type III; FOXO3: Forkhead box O3; GSK3: Glycogen synthase kinase 3. Ig: Immunoglobulin-like; IRS: Insulin receptor substrate; JAK: Janus kinases; Lan-2: Quadruple leptin mutein; LBD: Leptin-binding domain; Mcl-1: Induced myeloid leukemia cell differentiation; MEK: Mitogen-activated protein/ extracellular signal-regulated kinase; MERK: MAPKJERK; MMP: Matrix metalloproteinase; mTOR: Mechanistic target of rapamycin; NF-kB: Nuclear factor kappa-light-chain-enhancer of activated B cells; Ob: Obesity; ObR: Leptin receptor; PH: Pleckstrin homology; PI: Phosphatidylinositol 3phosphate; PI3K: Phosphatidylinositol 3-Kinase; PIP2: Phosphatidylinositol 4, 5-bisphosphate; PIP3: Phosphatidylinositol 3, 4, 5-trisphosphate; PK1: Protein kinase 1; PKB: Protein kinase B; PTEN: Phosphatase and tensin homolog; RhoA/ROCK: Ras homolog gene family, member A/Rho-associated protein kinase; SHLA: Superactive human leptin antagonist; SHP: Src Homology Phosphatase; STAT: Signal transducer and activator of transcription; XIAP: Xlinked inhibitor of apoptosis protein

\section{Acknowledgements}

The authors would like to thank the editors and anonymous reviewers.

\section{Funding}

Not applicable.

\section{Availability of data and materials}

Not applicable.

\section{Author's contributions}

IWA, AB, MZ, MA, OSK, SK, and KSB, performed literature review, compiled the data and write the manuscript. SU made extensive contributions to the design of the manuscript and revised it critically for important intellectual content. All authors read and approved the final manuscript.

\section{Ethics approval and consent to participate}

Not applicable.

\section{Consent for publication}

Not applicable.

\section{Competing interests}

The authors declare that they have no competing interests in this section.

\section{Publisher's Note}

Springer Nature remains neutral with regard to jurisdictional claims in published maps and institutional affiliations.

\section{Author details}

${ }^{1}$ Translational Research Institute, Academic Health System, Hamad Medical Corporation, POBox 3050, Doha, Qatar. ${ }^{2}$ Sidra Medicine, Research Branch, Doha, Qatar. ${ }^{3}$ Department of Biochemistry, Aligarh Muslim University, Aligarh, India. ${ }^{4}$ University of Illinois at Chicago, Illinois, USA.

Received: 9 November 2018 Accepted: 13 December 2018 Published online: 03 January 2019

\section{References}

1. Frederich RC, Hamann A, Anderson S, Lollmann B, Lowell BB, Flier JS. Leptin levels reflect body lipid content in mice: evidence for diet-induced resistance to leptin action. Nat Med. 1995:1:1311-4.

2. Ahima RS, Flier JS. Leptin. Annu Rev Physiol. 2000;62:413-37.
3. Pelleymounter MA, Cullen MJ, Baker MB, Hecht R, Winters D, Boone T, Collins $\mathrm{F}$. Effects of the obese gene product on body weight regulation in Ob/Ob mice. Science. 1995;269:540-3.

4. Sierra-Honigmann MR, Nath AK, Murakami C, Garcia-Cardena G, Papapetropoulos A, Sessa WC, Madge LA, Schechner JS, Schwabb MB, Polverini PJ, et al. Biological action of leptin as an angiogenic factor. Science. 1998;281:1683-6.

5. Banks WA. The many lives of leptin. Peptides. 2004;25:331-8.

6. Fruhbeck G, Jebb SA, Prentice AM. Leptin: physiology and pathophysiology. Clin Physiol. 1998;18:399-419.

7. Fruhbeck G. Peripheral actions of leptin and its involvement in disease. Nutr Rev. 2002;60:547-55 discussion S68-84, 85-47.

8. Muoio DM, Lynis Dohm G. Peripheral metabolic actions of leptin. Best Pract Res Clin Endocrinol Metab. 2002;16:653-66.

9. Galic S, Oakhill JS, Steinberg GR. Adipose tissue as an endocrine organ. Mol Cell Endocrinol. 2010;316:129-39.

10. Hancke K, Grubeck D, Hauser N, Kreienberg R, Weiss JM. Adipocyte fatty acid-binding protein as a novel prognostic factor in obese breast cancer patients. Breast Cancer Res Treat. 2010;119:367-7.

11. Garofalo C, Surmacz E. Leptin and cancer. J Cell Physiol. 2006;207:12-22.

12. Riolfi M, Ferla R, Del Valle L, Pina-Oviedo S, Scolaro L, Micciolo R, Guidi M, Terrasi M, Cetto GL, Surmacz E. Leptin and its receptor are overexpressed in brain tumors and correlate with the degree of malignancy. Brain Pathol. 2010;20:481-9.

13. Ishikawa M, Kitayama J, Nagawa H. Enhanced expression of leptin and leptin receptor (Ob-r) in human breast cancer. Clin Cancer Res. 2004;10: 4325-31.

14. Hoon Kim J, Lee SY, Myung SC, Kim YS, Kim TH, Kim MK. Clinical significance of the leptin and leptin receptor expressions in prostate tissues. Asian J Androl. 2008:10:923-8.

15. Uddin S, Bu R, Ahmed M, Abubaker J, Al-Dayel F, Bavi P, Al-Kuraya KS. Overexpression of leptin receptor predicts an unfavorable outcome in middle eastern ovarian cancer. Mol Cancer. 2009:8:74.

16. Uddin S, Bavi PP, Hussain AR, Alsbeih G, Al-Sanea N, Abduljabbar A, Ashari LH, Alhomoud S, Al-Dayel F, Ahmed M, et al. Leptin receptor expression in middle eastern colorectal cancer and its potential clinical implication. Carcinogenesis. 2009;30:1832-40

17. Liu H, Wan D, Pan Z, Cao L, Wu X, Lu Z, Kang T. Expression and biological significance of leptin, leptin receptor, vegf, and cd34 in colorectal carcinoma. Cell Biochem Biophys. 2011;60:241-4.

18. Kato S, Abarzua-Catalan L, Trigo C, Delpiano A, Sanhueza C, Garcia K, Ibanez C, Hormazabal K, Diaz D, Branes J, et al. Leptin stimulates migration and invasion and maintains cancer stem-like properties in ovarian cancer cells: An explanation for poor outcomes in obese women. Oncotarget. 2015;6: 21100-19

19. Bjorbaek C, Uotani S, da Silva B, Flier JS. Divergent signaling capacities of the long and short isoforms of the leptin receptor. J Biol Chem. 1997:272: 32686-95.

20. Tartaglia LA, Dembski M, Weng X, Deng N, Culpepper J, Devos R, Richards GJ, Campfield LA, Clark FT, Deeds J, et al. Identification and expression cloning of a leptin receptor, Ob-r. Cell. 1995:83:1263-71.

21. Zhang Y, Proenca R, Maffei M, Barone M, Leopold L, Friedman JM. Positional cloning of the mouse obese gene and its human homologue. Nature. 1994; 372:425-32.

22. Lee GH, Proenca R, Montez JM, Carroll KM, Darvishzadeh JG, Lee Jl, Friedman JM. Abnormal splicing of the leptin receptor in diabetic mice. Nature. 1996:379:632-5.

23. Haniu M, Arakawa T, Bures EJ, Young Y, Hui JO, Rohde MF, Welcher AA, Horan T. Human leptin receptor. Determination of disulfide structure and $n-$ glycosylation sites of the extracellular domain. J Biol Chem. 1998;273:28691-9.

24. Ahima RS, Prabakaran D, Mantzoros C, Qu D, Lowell B, Maratos-Flier E, Flier JS. Role of leptin in the neuroendocrine response to fasting. Nature. 1996; 382:250-2.

25. Chua SC Jr, Chung WK, Wu-Peng XS, Zhang Y, Liu SM, Tartaglia L, Leibel RL. Phenotypes of mouse diabetes and rat fatty due to mutations in the $\mathrm{Ob}$ (leptin) receptor. Science. 1996:271:994-6.

26. Myers MG Jr. Leptin receptor signaling and the regulation of mammalian physiology. Recent Prog Horm Res. 2004;59:287-304.

27. Ghilardi N, Ziegler S, Wiestner A, Stoffel R, Heim MH, Skoda RC. Defective stat signaling by the leptin receptor in diabetic mice. Proc Natl Acad Sci U S A. 1996;93:6231-5 
28. Eisenberg A, Biener E, Charlier M, Krishnan RV, Djiane J, Herman B, Gertler A. Transactivation of erbb2 by short and long isoforms of leptin receptors. FEBS Lett. 2004;565:139-42.

29. Gao J, Tian J, Lv Y, Shi F, Kong F, Shi H, Zhao L. Leptin induces functional activation of cyclooxygenase-2 through jak2/stat3, mapk/erk, and pi3k/akt pathways in human endometrial cancer cells. Cancer Sci. 2009;100:389-95.

30. Aleffi S, Petrai I, Bertolani C, Parola M, Colombatto S, Novo E, Vizzutti F, Anania FA, Milani S, Rombouts K, et al. Upregulation of proinflammatory and proangiogenic cytokines by leptin in human hepatic stellate cells. Hepatology. 2005;42:1339-48.

31. Fruhbeck G. A heliocentric view of leptin. Proc Nutr Soc. 2001;60:301-18.

32. Saxena NK, Sharma D, Ding X, Lin S, Marra F, Merlin D, Anania FA. Concomitant activation of the jak/stat, pi3k/akt, and erk signaling is involved in leptin-mediated promotion of invasion and migration of hepatocellular carcinoma cells. Cancer Res. 2007;67:2497-507.

33. Sharma D, Saxena NK, Vertino PM, Anania FA. Leptin promotes the proliferative response and invasiveness in human endometrial cancer cells by activating multiple signal-transduction pathways. Endocr Relat Cancer. 2006;13:629-40.

34. Bahrenberg G, Behrmann I, Barthel A, Hekerman P, Heinrich PC, Joost HG, Becker W. Identification of the critical sequence elements in the cytoplasmic domain of leptin receptor isoforms required for janus kinase/signal transducer and activator of transcription activation by receptor heterodimers. Mol Endocrinol. 2002;16:859-72.

35. Darnell JE Jr, Kerr IM, Stark GR. Jak-stat pathways and transcriptional activation in response to ifns and other extracellular signaling proteins. Science. 1994;264:1415-21.

36. Jiang N, He TC, Miyajima A, Wojchowski DM. The box1 domain of the erythropoietin receptor specifies janus kinase 2 activation and functions mitogenically within an interleukin 2 beta-receptor chimera. J Biol Chem. 1996;271:16472-6.

37. Kloek C, Haq AK, Dunn SL, Lavery HJ, Banks AS, Myers MG Jr. Regulation of jak kinases by intracellular leptin receptor sequences. J Biol Chem. 2002;277: 41547-55.

38. Hoda MR, Keely SJ, Bertelsen LS, Junger WG, Dharmasena D, Barrett KE. Leptin acts as a mitogenic and antiapoptotic factor for colonic cancer cells. Br J Surg. 2007;94:346-54.

39. Chen C, Chang YC, Liu CL, Chang KJ, Guo IC. Leptin-induced growth of human zr-75-1 breast cancer cells is associated with up-regulation of cyclin d1 and c-myc and down-regulation of tumor suppressor p53 and p21waf1/ cip1. Breast Cancer Res Treat. 2006;98:121-32.

40. Ogunwobi O, Mutungi G, Beales IL. Leptin stimulates proliferation and inhibits apoptosis in barrett's esophageal adenocarcinoma cells by cyclooxygenase-2-dependent, prostaglandin-e2-mediated transactivation of the epidermal growth factor receptor and c-Jun nh2-terminal kinase activation. Endocrinology. 2006;147:4505-16.

41. Osaki M, Oshimura M, Ito H. Pi3k-akt pathway: its functions and alterations in human cancer. Apoptosis : an international journal on programmed cel death. 2004:9:667-76.

42. Hegyi K, Fulop K, Kovacs K, Toth S, Falus A. Leptin-induced signal transduction pathways. Cell Biol Int. 2004;28:159-69.

43. Matsuoka T, Yashiro M. The role of pi3k/akt/mtor signaling in gastric carcinoma. Cancers (Basel). 2014;6:1441-63.

44. Hoffmann M, Fiedor E, Ptak A. 17beta-estradiol reverses leptin-inducing ovarian cancer cell migration by the pi3k/akt signaling pathway. Reprod Sci. 2016;23:1600-8.

45. Chen C, Chang YC, Lan MS, Breslin M. Leptin stimulates ovarian cancer cell growth and inhibits apoptosis by increasing cyclin d1 and mcl-1 expression via the activation of the mek/erk1/2 and pi3k/akt signaling pathways. Int J Oncol. 2013;42:1113-9.

46. Uddin S, Ahmed M, Hussain A, Assad L, Al-Dayel F, Bavi P, Al-Kuraya KS, Munkarah A. Cyclooxygenase-2 inhibition inhibits pi3k/akt kinase activity in epithelial ovarian cancer. Int J Cancer. 2010;126:382-94.

47. Yoon AR, Stasinopoulos I, Kim JH, Yong HM, Kilic O, Wirtz D, Bhujwalla ZM, An SS. Cox-2 dependent regulation of mechanotransduction in human breast cancer cells. Cancer Biol Ther. 2015;16:430-7.

48. Ogunwobi OO, Liu C. Hepatocyte growth factor upregulation promotes carcinogenesis and epithelial-mesenchymal transition in hepatocellular carcinoma via akt and cox-2 pathways. Clin Exp Metastasis. 2011;28:721-31.

49. Ogunwobi $\mathrm{OO}$, Beales IL. The anti-apoptotic and growth stimulatory actions of leptin in human colon cancer cells involves activation of jnk mitogen activated protein kinase, jak2 and pi3 kinase/akt. Int J Color Dis. 2007;22: 401-9.
50. Ghasemi A, Hashemy SI, Aghaei M, Panjehpour M. Rhoa/rock pathway mediates leptin-induced upa expression to promote cell invasion in ovarian cancer cells. Cell Signal. 2017;32:104-14.

51. Dass K, Ahmad A, Azmi AS, Sarkar SH, Sarkar FH. Evolving role of upa/upar system in human cancers. Cancer Treat Rev. 2008;34:122-36.

52. Siegel R, Naishadham D, Jemal A. Cancer statistics, 2012. CA Cancer J Clin. 2012;62:10-29.

53. Auersperg N, Wong AS, Choi KC, Kang SK, Leung PC. Ovarian surface epithelium: biology, endocrinology, and pathology. Endocr Rev. 2001;22:255-88.

54. Salzberg M, Thurlimann B, Bonnefois H, Fink D, Rochlitz C, von Moos R, Senn $\mathrm{H}$. Current concepts of treatment strategies in advanced or recurrent ovarian cancer. Oncology. 2005;68:293-8.

55. Fung-Kee-Fung M, Oliver T, Elit L, Oza A, Hirte HW, Bryson P. Optimal chemotherapy treatment for women with recurrent ovarian cancer. Curr Oncol. 2007:14:195-208.

56. McGuire WP, Ozols RF. Chemotherapy of advanced ovarian cancer. Semin Oncol. 1998:25:340-8.

57. Abu-Abid S, Szold A, Klausner J. Obesity and cancer. J Med. 2002;33:73-86

58. Choi JH, Park SH, Leung PC, Choi KC. Expression of leptin receptors and potential effects of leptin on the cell growth and activation of mitogenactivated protein kinases in ovarian cancer cells. J Clin Endocrinol Metab. 2005;90:207-10

59. Jin JH, Kim HJ, Kim CY, Kim YH, Ju W, Kim SC. Association of plasma adiponectin and leptin levels with the development and progression of ovarian cancer. Obstet Gynecol Sci. 2016;59:279-85.

60. Luhn P, Dallal CM, Weiss JM, Black A, Huang WY, Lacey JV Jr, Hayes RB, Stanczyk FZ, Wentzensen N, Brinton LA. Circulating adipokine levels and endometrial cancer risk in the prostate, lung, colorectal, and ovarian cancer screening trial. Cancer epidemiology, biomarkers \& prevention : a publication of the American Association for Cancer Research, cosponsored by the American Society of Preventive Oncology. 2013;22:1304-12.

61. Grabowski JP, Markowska A, Markowska J. Evaluation of leptin serum concentrations during surgery and first-line chemotherapy in primary epithelial ovarian cancer patients. Contemp Oncol (Pozn). 2014;18:318-22.

62. Mor G, Visintin I, Lai Y, Zhao H, Schwartz P, Rutherford T, Yue L, Bray-Ward P, Ward DC. Serum protein markers for early detection of ovarian cancer. Proc Natl Acad Sci U S A. 2005;102:7677-82.

63. Visintin I, Feng Z, Longton G, Ward DC, Alvero AB, Lai Y, Tenthorey J, Leiser A, Flores-Saaib R, Yu H, et al. Diagnostic markers for early detection of ovarian cancer. Clinical cancer research : an official journal of the American Association for Cancer Research. 2008;14:1065-72.

64. Leitzmann MF, Koebnick C, Danforth KN, Brinton LA, Moore SC, Hollenbeck AR, Schatzkin A, Lacey JV Jr. Body mass index and risk of ovarian cancer. Cancer. 2009;115:812-22.

65. Wei X, Liu Y, Gong C, Ji T, Zhou X, Zhang T, Wan D, Xu S, Jin P, Yang X, Li X, Ma D, Yang Z, Gao Q. Targeting Leptin as a Therapeutic Strategy against Ovarian Cancer Peritoneal Metastasis. Anticancer Agents Med Chem. 2017; 17(8):1093-101.

66. Cuello-Fredes M, Kato S, Abarzua-Catalan L, Delpiano A, Trigo C, Garcia K, Sanhueza C, Ibanez C, Branes J, Castellon E, et al. Leptin promotes a more aggresive behavior of ovarian cancer cells: a potential explanation for a worse prognosis in obese ovarian cancer patients: Igcs-0095 ovarian cancer. Int J Gynecol Cancer. 2015;25(Suppl 1):67.

67. Tessitore L, Vizio B, Pesola D, Cecchini F, Mussa A, Argiles JM, Benedetto C. Adipocyte expression and circulating levels of leptin increase in both gynaecological and breast cancer patients. Int J Oncol. 2004;24:1529-35.

68. Mantzos F, Vanakara P, Samara S, Wozniak G, Kollia P, Messinis I, Hatzitheofilou C. Leptin receptor expression in neoplastic and normal ovarian and endometrial tissue. Eur J Gynaecol Oncol. 2011;32:84-6.

69. Xu X, Dong Z, Li Y, Yang Y, Yuan Z, Qu X, Kong B. The upregulation of signal transducer and activator of transcription 5-dependent microrna-182 and microrna-96 promotes ovarian cancer cell proliferation by targeting forkhead box 03 upon leptin stimulation. Int J Biochem Cell Biol. 2013;45:536-45.

70. Mendez-Lopez LF, Davila-Rodriguez MI, Zavala-Pompa A, Torres-Lopez E, Gonzalez-Martinez BE, Lopez-Cabanillas-Lomeli M. Expression of leptin receptor in endometrial biopsies of endometrial and ovarian cancer patients. Biomed Rep. 2013;1:659-63.

71. Uddin S, Bavi P, Siraj AK, Ahmed M, Al-Rasheed M, Hussain AR, Ahmed M, Amin T, Alzahrani A, Al-Dayel F, et al. Leptin-r and its association with pi3k akt signaling pathway in papillary thyroid carcinoma. Endocr Relat Cancer. 2010;17:191-202. 
72. Uddin S, Mohammad RM. Role of leptin and leptin receptors in hematological malignancies. Leuk Lymphoma. 2016;57:10-6.

73. Mitchell M, Armstrong DT, Robker RL, Norman RJ. Adipokines: implications for female fertility and obesity. Reproduction. 2005;130:583-97.

74. Ptak A, Kolaczkowska E, Gregoraszczuk EL. Leptin stimulation of cell cycle and inhibition of apoptosis gene and protein expression in ovcar-3 ovarian cancer cells. Endocrine. 2013;43:394-403.

75. Fiedor $\mathrm{E}$, Gregoraszczuk EL. The molecular mechanism of action of superactive human leptin antagonist (shla) and quadruple leptin mutein lan-2 on human ovarian epithelial cell lines. Cancer Chemother Pharmacol. 2016;78:611-22.

76. Wei X, Liu Y, Gong C, Ji T, Zhou X, Zhang T, Wan D, Xu S, Jin P, Yang X, et al. Targeting leptin as a therapeutic strategy against ovarian cancer peritoneal metastasis. Anti Cancer Agents Med Chem. 2017;17:1093-101.

77. Karahanoglu E, Adanir I, Boyraz G, Sahin N, Tuncer ZS. Preoperative serum leptin levels in patients with endometrial cancer and its correlation with prognostic variables. Eur J Gynaecol Oncol. 2012;33:278-80.

Ready to submit your research? Choose BMC and benefit from:

- fast, convenient online submission

- thorough peer review by experienced researchers in your field

- rapid publication on acceptance

- support for research data, including large and complex data types

- gold Open Access which fosters wider collaboration and increased citations

- maximum visibility for your research: over $100 \mathrm{M}$ website views per year

At $\mathrm{BMC}$, research is always in progress.

Learn more biomedcentral.com/submissions 